\title{
Congenital Pseudarthrosis of Tibia
}

National Cancer Institute

\section{Source}

National Cancer Institute. Congenital Pseudarthrosis of Tibia. NCI Thesaurus. Code C132080.

A condition characterized by non-union of the tibia, which is present at birth. It is usually associated with neurofibromatosis type 1. 